\title{
Perbedaan Perceived Quality Konsumen Yang Menggunakan Make Up X dan Y
}

\author{
Rifda Aidil Fira \\ Program Studi Psikologi, Fakultas Kedokteran, \\ Universitas Syiah Kuala \\ firarifda9494@gmail.com \\ Eka Dian Aprilia \\ Program Studi Psikologi, Fakultas Kedokteran, \\ Universitas Syiah Kuala \\ eka.aprilia@unsyiah.ac.id
}

\begin{abstract}
Abstrak
Kualitas sebuah produk adalah salah satu hal yang dipertimbangkan konsumen dalam membeli. Persepsi konsumen terhadap kualitas sebuah produk sangatlah penting dalam proses pembelian, apabila konsumen tidak mempunyai persepsi yang bagus terhadap produk dari merk tertentu maka kecil kemungkinan konsumen akan membeli produknya. Banyaknya merk-merk di pasar Indonesia, baik merk global seperti merk $\mathrm{X}$ dan merk lokal seperti merek Y. Agar kedua produk dari merk tersebut menjadi pilihan atau dapat diterima konsumen, maka harus memiliki Perceived Quality yang baik. Tujuan penelitian ini adalah untuk mengetahui perbedaan perceived quality konsumen yang menggunakan make up $\mathrm{X}$ dan Y. Teknik pengambilan sampel yang digunakan adalah quota sampling, dengan jumlah sampel penelitian terdiri dari 50 konsumen menggunakan make up $\mathrm{X}$ dan 50 konsumen menggunakan make up Y. Hasil uji analisis hipotesis dengan menggunakan Independent Sample t-test menunjukkan bahwa nilai signifikansi $\mathrm{p}=0,754(\mathrm{p}<0,05)$. Hal ini mengindikasikan bahwa tidak terdapat perbedaan perceived quality konsumen yang menggunakan make up $\mathrm{X}$ dan $\mathrm{Y}$.
\end{abstract}

Kata kunci: perceived quality; make up $x$; make up $y$

\section{Pendahuluan}

Masa dewasa awal merupakan masa peralihan dari masa remaja menuju dewasa (Papalia, Old \& Feldman, 2008). Dewasa awal dimulai sejak usia 18 
hingga 40 tahun (Hurlock, 1999). Salah satu tugas pada tahap perkembangan dewasa awal ialah mencari dan menemukan pasangan hidup (Papalia, Old \& Feldman, 2008). Proses mencari dan menemukan pasangan hidup menyebabkan seorang pada masa perkembangan dewasa awal ingin terlihat lebih cantik dan menarik dihadapan pasangan serta lingkungannya (Sunartio, Sukamto \& Dianovinima, 2012).

Kecantikan yang ditampilkan oleh wanita akan menjadikannya tampak lebih percaya diri (Wulansari \& Budiadi, 2015). Salah satu yang menjadi kebutuhan seorang wanita untuk cantik yaitu dengan menggunakan kosmetik (Ferrinadewi, 2005). Kosmetik bagi wanita adalah bagian yang tidak terpisahkan dari hidupnya (Yuwanto, 2014). Salah satu jenis kosmetik yang paling umum digunakan oleh wanita adalah make up (Pramungnitias, 2007).

Make up merupakan bagian dari kosmetik yang memiliki fungsi sebagai sarana yang digunakan oleh wanita dalam mewujudkan keinginannya seperti memenuhi tuntutan, menjaga penampilan diri, menjadi pribadi yang layak dihargai, serta diterima dilingkungan sekitar (Natalia \& Pramadi, 2001).

Korchi, Pelle de Queral, Gazano dan Aubert (2008) menyatakan bahwa make up secara psikologi memiliki dua fungsi yaitu fungsi seduction dan camouflage. Fungsi seduction artinya individu menggunakan make up untuk meningkatkan penampilan diri dan merasa bahwa dirinya terlihat menarik, sedangkan fungsi camouflage artinya individu menggunakan make up untuk menutupi kekurangan fisik dirinya.

Salah satu hal yang dipertimbangkan oleh wanita dalam memilih make up adalah merek (Syahputri, 2013). Merek adalah nama, istilah, tanda, simbol, desain atau kombinasi keseluruhan yang ditujukan untuk mengidentifikasikan barang atau jasa yang ditawarkan perusahaan serta sebagai diferensiasi produk (Kotler \& Armstrong, 1997). Merek memegang peranan yang sangat penting, salah satunya yakni menjembatani harapan konsumen pada saat pemasaran yang menjanjikan sesuatu pada konsumen, dengan demikian dapat diketahui ikatan emosional yang tercipta antara konsumen dengan perusahaan penghasil produk melalui merek (Durianto, 2001). Aaker \& Joachimstahler (2000) menyebutkan bahwa merek 
memiliki manfaat yang terdiri dari 2 jenis yaitu manfaat fungsional dan manfaat emosional. Manfaat fungsional mengacu pada kemampuan fungsi produk yang ditawarkan, sedangkan manfaat emosional adalah kemampuan merek untuk membuat penggunanya merasakan sesuatu selama proses pembelian atau selama menggunakan (Ferrinadewi, 2008).

Terdapat merek-merek make up yang berada di pasar Indonesia, baik make up merek global dan merek lokal atau merek domestik dan merek global (Erdalina \& Evalita, 2015). Merek global atau global brand adalah produk-produk yang memiliki merek dagang yang sudah dikenal luas diberbagai negara dengan sistem pemasaran terstruktur yang sama dibanyak negara (Tati, Suharyono \& Yulianto, 2015).

Salah satu merek global yang bertahan di pasar kosmetik Indonesia adalah merek X (Nasution, 2011).X adalah perusahaan kosmetik yang bermula di Stockholm, Swedia pada tahun 1967 oleh dua orang bersaudara yaitu Jonas dan Robert Af Jochnick (Sulystyari \& Yoestini, 2012). Merek X tidak pernah melupakan konsep awal dalam berbisnis yaitu Natural Swedish Cosmetics yang menawarkan produk kosmetik dan perawatan kulit alami yang berkualitas tinggi melalui jaringan penjual mandiri (independent sales force) yang berbeda dengan sistem retail pada umumnya (Nasution, 2011).

Pada pasar dimana merek global tidak dikenal, banyak perusahaan membeli merek produk lokal yang diinginkan konsumen dan diperbaharui kembali, dikemas kembali, dan kemudian diluncurkan kembali dengan citra yang baru, hal tersebut berdampak terhadap merek-merek lokal (Cateora, 2007). Merek lokal merupakan merek atau produk yang diproduksi didalam negeri untuk pasar nasional tertentu dan biasanya hanya dapat diperoleh di wilayah tertentu (Putri \& Prihastuty, 2014).Salah satu merek lokal adalah merek Y.

Merek Y merupakan merek produk lokal unggulan dari PT. Paragon Technology Innovation (Habibah \& Sumiati, 2016). Merek Y mengusung tiga prinsip kecantikan yakni pure and safe, artinya merek mengandung bahan baku yang aman dan halal, diciptakan untuk kenyamanan dan ketenangan wanita yang menggunakannya. Beauty expert, artinya citra awal merek Y sebagai kosmetik 
yang ditujukan untuk wanita muslim namun telah berkembang menjadi produk yang dapat dinikmati oleh kalangan yang lebih luas. Inspiring beauty, artinya, merek Y menyakini bahwa kecantikan bukanlah hanya tampak dari luar, tapi juga harus dari jiwa (Ybeauty, 2013).

Agar sebuah merek menjadi pilihan atau dapat diterima konsumen, maka harus memiliki Perceived Quality yang baik bagi konsumen (Wisnu \&Hermawan, 2011). Aaker (1991) menyatakan Perceived Quality adalah persepsi pelanggan atau konsumen terhadap keseluruhan kualitas atau keunggulan suatu produk atau jasa layanan yang berkenaan dengan maksud yang diharapkan. Perceived Quality menjadi dasar yang penting bagi konsumen dalam memutuskan pembelian (Hgau, Mintarti \& Kuleh, 2012). Durianto (2004) menyebutkan bahwa Perceived Quality merupakan persepsi konsumen terhadap suatu produk atau jasa, jika persepsi konsumen negatif maka produk tidak disukai atau tidak akan bertahan lama, sebaliknya jika persepsi konsumen positif maka produk tersebut disukai oleh konsumen.

Perceived Quality bersifat subjektif artinya konsumen memiliki pemahaman yang berbeda terhadap merek dari suatu produk (Aaker, 1991). Hal ini berdasarkan pengalaman konsumen dalam menggunakan produk atau dengan pengaruh lingkungan sekitar seperti keluarga dan teman (Fitriyah \& Iriani, 2014). Putri (2012) mengatakan bahwa Perceived Quality pada setiap individu berbedabeda didasarkan pada usia serta status dalam lingkungan hal ini disebabkan dari pengalaman serta pengetahuan, kebutuhan individu dalam lingkungannya.

Penelitian yang dilakukan oleh Zareei dan Ashtiani (2015) menyatakan bahwa terdapat perbedaan Perceived Quality pada merek lokal dan merek global. Merek produk global dianggap lebih berkualitas dan superior dibandingkan dengan merek produk lokal. Selanjutnya Putri dan Prihastuty (2014) juga menyebutkan bahwa terdapat perbedaanPerceived Quality pada merek kosmetik lokal dan merek kosmetik global apabila dianalisa lebih lanjut melalui dimensidimensi.Pada merek kosmetik lokal memiliki keunggulan pada dimensi performance dan durability. Performance pada merek produk lokal bekerja secara efektif sehingga konsumen puas pada hasil yang diharapkan, durability pada 
produk dianggap lebih fleksibel di berbagai situasi sehari-hari, sementara merek kosmetik global memiliki keunggulan pada dimensi reliability, serviceability serta fit and finish produk. Keandalan merek produk global dapat diandalkan sebagai solusi masalah kulit dan konsisten pada setiap pemakaian serta pelayanan yang diberikan oleh pramuniaga yang cukup baik dan mampu memberikan informasi yang jelas pada pembeli.

Berdasarkan latar belakang yang telah dikemukan diatas, peneliti tertarik untuk melakukan penelitian mengenai "Perbedaan Perceived Quality konsumen yang menggunakan make up $\mathrm{X}$ dan $\mathrm{Y}^{\prime}$.

\section{Metode Penelitian}

Penelitian ini menggunakan pendekatan kuantitatif dengan jenis penelitian komparatif. Adapun populasi dari penelitian ini adalah wanita dewasa yang berada di Banda Aceh. Teknik pengampilan sampel penelitian menggunakan teknik nonprobability sampling, dengan menggunakan teknik quota sampling. Peneliti menentukan jumlah sampel penelitian yang digunakan dalam penelitian sebanyak 100 sampel (terdiri dari 50 sampel konsumen make up $\mathrm{X}$ dan 50 sampel konsumen make up Y). Adapun kriteria sampel secara umum pada penelitian ini adalah : a) wanita yang berdomisili di Banda Aceh, b) menggunakan produk make up $\mathrm{X}$ ataupun $\mathrm{Y}, \mathrm{c}$ ) berada pada tahap dewasa awal dengan dengan usia 18 tahun hingga 40 tahun, d) bekerja dan tidak bekerja, e) bersedia menjadi responden dalam penelitian.

Pengumpulan data yang digunakan dalam penelitian ini adalah Skala Perceived Quality oleh Aaker (1991) yang disusun oleh peneliti berdasarkan 7 dimensi Perceived Quality yaitu performance, features, conformance with specification, reliability, durability, serviceability, danfit and finish.

\section{Hasil dan Pembahasan}


Tabel 1. Deskripsi Data Penelitian Perceived Quality yang menggunakan produk make up X dan $Y$

\begin{tabular}{ccccccccc} 
Perceived & \multicolumn{3}{c}{ Data Hipotetik } & \multicolumn{5}{c}{ Data Empirik } \\
Quality & $\mathbf{X}_{\text {max }}$ & $\mathbf{X}_{\text {min }}$ & Mean & STD & $\begin{array}{c}\mathbf{X}_{\text {ma }} \\
\mathbf{x}\end{array}$ & $\mathbf{X}_{\text {min }}$ & Mean & STD \\
\hline X & 104 & 26 & 65 & 13 & 100 & 62 & 76,98 & 8,565 \\
Y & 104 & 26 & 65 & 13 & 91 & 65 & 77,44 & 5,810
\end{tabular}

Berdasarkan hasil statistik data penelitian, analisis deskriptif secara hipotetik menunjukkan bahwa skor minimal adalah 28 dan skor maksimal 196. Nilai rata-rata yang diperoleh adalah 112 dan standart deviasi 28. Data deskriptif di atas dapat digunakan untuk membagi pengkategorian sampel penelitian yang terdiri dari tiga kategori, yaitu rendah, tidak terkategori dan tinggi. Pembagian kategori sampel yang digunakan peneliti adalah kategorisasi berdasarkan model distribusi normal dengan kategorisasi jenjang (ordinal). Menurut Azwar (2013) kategorisasi jenjang (ordinal) merupakan kategorisasi yang menempatkan individu kedalam kelompok-kelompok yang posisinya berjenjang menurut suatu kontinum berdasarkan atribut yang diukur. Berikut kategorisasi sampel employability:

Tabel 2. Kategorisasi Perceived Quality yang menggunakan make up X dan Y

\begin{tabular}{|c|c|c|c|c|c|}
\hline \multirow{2}{*}{$\begin{array}{l}\text { Rumus Norma } \\
\text { Kategorisasi }\end{array}$} & \multirow[t]{2}{*}{ Kategorisasi } & \multicolumn{2}{|c|}{ Jumlah } & \multicolumn{2}{|c|}{ Persentase \% } \\
\hline & & $\mathbf{X}$ & $\mathbf{Y}$ & $\mathbf{X}$ & $\mathbf{Y}$ \\
\hline$X<52$ & Rendah & 0 & 0 & 0 & 0 \\
\hline $52 \leq X \leq 78$ & Sedang & 31 & 24 & 62 & 48 \\
\hline $78 \leq X$ & Tinggi & 19 & 26 & 38 & 52 \\
\hline \multicolumn{2}{|c|}{ Total } & 50 & 50 & 100 & 100 \\
\hline
\end{tabular}


Tabel 3. Kategorisasi Perceived Quality make up X dan Y berdasarkan frekuensi jawaban konsumen perdimensi

\begin{tabular}{lcccc}
\hline \multicolumn{1}{c}{ Dimensi } & Merek & \multicolumn{3}{c}{ Kategorisasi } \\
\cline { 3 - 5 } & & Rendah & Sedang & Tinggi \\
\hline Performance & $\mathrm{X}$ & 8 & 37 & $5^{*}$ \\
& $\mathrm{Y}$ & 12 & 32 & 6 \\
\hline Features & $\mathrm{X}$ & 37 & 7 & 6 \\
& $\mathrm{Y}$ & 11 & 29 & $10^{*}$ \\
\hline Conformance with & $\mathrm{X}$ & 34 & 10 & $6^{*}$ \\
specification & $\mathrm{Y}$ & 36 & 6 & 8 \\
\hline Reliability & $\mathrm{X}$ & 6 & 40 & $4^{*}$ \\
& $\mathrm{Y}$ & 12 & 20 & 18 \\
\hline Durability & $\mathrm{X}$ & 6 & 39 & $5^{*}$ \\
& $\mathrm{Y}$ & 10 & 24 & 6 \\
\hline Service ability & $\mathrm{X}$ & 5 & 40 & 5 \\
& $\mathrm{Y}$ & 4 & 37 & $9^{*}$ \\
\hline Fit and finish & $\mathrm{X}$ & 11 & 31 & 8 \\
& $\mathrm{Y}$ & 5 & 39 & $6^{*}$ \\
\hline
\end{tabular}

Keterangan :

(*) = Merupakan tingkat Perceived Quality yang lebih tinggi berdasarkan perdimensi

\section{Uji Asumsi}

Hasil uji asumsi menunjukkan bahwa data berdistribusi normal dan tidak homogen. Hal tersebut dilihat dari hasil analisis variabel Perceived Qualitydiperoleh dari hasil make up X memiliki sebaran normal (K-Sz $=0,343$ dengan $\mathrm{p}>0,05)$ dan pada konsumen make up $\mathrm{Y}$ memiliki sebaran normal (K$\mathrm{Sz}=0,968$ dengan $\mathrm{p}>0,05$ ). Uji homogenitas didapatkan nilai signifikansi 0,000. Nilai signifikansi 0,000 tersebut merupakan nilai lebih dari $0,05(\mathrm{p}=0,000>$ 0,05).Setelah uji asumsi terpenuhi, maka dilakukan uji hipotesis menggunakan teknik parametrik yaitu Independent Sample t- test.

\section{Uji Hipotesis}

Hasil uji hipotesis menunjukkan nilai signifikansi $\mathrm{p}=0,754(\mathrm{p}<0,05)$ dengan $\mathrm{Z}=0,938$ pada make up $\mathrm{X}$ dan $\mathrm{Z}=0,493$ pada make up $\mathrm{Y}$. Hipotesis yang diperoleh adalah tidak terdapat perbedaan Perceived Quality konsumen yang menggunakan make up $\mathrm{X}$ dan $\mathrm{Y}$.

\section{Diskusi}

Penelitian ini bertujuan melihat Perceived Quality konsumen yang menggunakan make up $\mathrm{X}$ dan $\mathrm{Y}$. Berdasarkan analisis yang didapatkan dari 
penelitian yang telah dilakukan pada konsumen make up $\mathrm{X}$ dan $\mathrm{Y}$ menunjukkan bahwa nilai signifikansi $\mathrm{p}=0,754(\mathrm{p}<0,05)$. Hal ini menunjukkan bahwa hipotesis ditolak sehingga dapat dikatakan bahwa tidak terdapat perbedaan Perceived Quality konsumen yang menggunakan produk make up $\mathrm{X}$ dan $\mathrm{Y}$. Artinya Perceived Quality make up X sebagai merek global di anggap sama dengan Perceived Quality make up Y sebagai merek lokal. Hal ini dikarenakan merek $\mathrm{X}$ dan Y sama-sama memiliki konsep alami serta membidik pasar yang sama salah satunya dewasa. Hasil penelitian ini sejalan dengan penelitian yang dilakukan oleh Lee, Knight dan Kim (2008) yang menyatakan bahwa tidak terdapat perbedaan Perceived Quality antara merk lokal dan global hal ini dikarenakan bahwa konsumen lebih peduli terhadap kualitas produk dari merek dibandingkan dengan asal produk tersebut. Merk global memiliki kesan yang baik namun kualitas produk lokal pun cukup baik sehingga konsumen tidak terlalu memperhatikan apakah produk yang digunakan berasal dari dalam maupun luar.

Perceived Quality menjadi alasan untuk membeli produk dari suatu merk bagi konsumen dalam situasi tertentu (Choy, 2011).Perceived Quality yang tinggi terhadap suatu merk akan mempengaruhi harapan konsumen terhadap merk tersebut (Aaker, 1991). Semakin tinggi Perceived Quality konsumen terhadap suatu merk, maka semakin tinggi kecenderungan yang dimiliki konsumen untuk membeli kembali produk dari merk tersebut begitu juga sebaliknya semakin rendahPerceived Qualitykonsumen terhadap suatu merk maka semakin rendah pula keinginan konsumen untuk membeli produk dari merk tersebut (Belopa, 2015).

Beberapa faktor yang menyebabkan tidak adanya perbedaan Perceived Qualitykonsumen pada make up X sebagai merek global dan Y sebagai merek lokal dapat dijelaskan dari beberapa data demografi yang diperoleh peneliti. Pertama, dari segi faktor usia, peneliti mengambil sampel penelitian pada kelompok usia dewasa awal yang berkisar 18-40 tahun. Sebuah riset yang dilakukan oleh Chao dan Schor (1996) pada 20 wanita dewasa berhasil membuktikan bahwa pada umumnya konsumen tidak mempermasalahkan merek dan lebih mengutamakan kualitas produk ketika memutuskan memilih dan 
menggunakan kosmetik-kosmetik yang tidak terlihat langsung seperti pelembab, alas bedak, pensil alis, blush on dan lain-lain. Sebaliknya, konsumen cenderung mementingkan nama merek ketika produk yang digunakan sifatnya nyata seperti lipstik (Ferrinadewi, 2005).

Kedua berdasarkan status pekerjaan konsumen yang dibagi menjadi bekerja dan tidak bekerja.Penelitian Roy dan Chau (2011) menunjukkan bahwa tidak ada perbedaan Perceived Quality terhadap merek global maupun lokal, namun biasanya subjek dengan status ekonomi lebih tinggi seperti wanita bekerja memiliki kesadaran yang lebih tinggi terhadap merek global.Eksistensi wanita yang bekerja memiliki kondisi yang lebih kompleks, dibandingkan dengan wanita yang tidak bekerja sebab wanita yang bekerja harus menjaga penampilannya tidak hanya dirumah namun juga ditempat kerja.Menurut Bartos (dalam Damayanti, 2002) wanita bekerja lebih sering menggunakan make up daripada wanita yang tidak bekerja, hal tersebut dikarenakan make up merupakan sarana yang digunakan wanita untuk menampilkan karakter dirinya dan dengan make up wanita bekerja dapat mengembangkan kepercayaan dirinya.

Ketiga berdasarkan lama dalam menggunakan produk dari kedua merek, konsumen pada penelitian ini mendominasi waktu menggunakan 1-2 tahun, hal tersebut diasumsikan konsumen memiliki pengalaman yang cukup terkait dengan merek dari produk yang digunakan. Wangenheirn dan Bayon (dalam Ferrianadewi, 2005) mengatakan bahwa melalui lamanya pengalaman menggunakan suatu merek, konsumen mendapatkan informasi bagaimana kinerja produk dari suatu merek dapat memenuhi harapannya, dengan demikian dapat disimpulkan bahwa pengalaman merupakan bentuk informasi yang paling bertahan dalammemori manusia (Ferrianadewi, 2005).Yoo (2000) menyebutkan bahwa Perceived Quality dipengaruhi oleh pengalaman pribadi terkait dengan merek, situasi saat menggunakan dan kebutuhan khusus setiap konsumen.Perceived Quality yang tinggi mempunyai arti bahwa melalui pengalaman yang panjang dengan merek, konsumen dapat mengenali perbedaan dan keunggulan merek tersebut terhadap merek lain.Perceived Quality yang tinggi akan mengarahkan konsumen untuk memilih suatu merek (Tarmedi \& Asri, 
ISSN : $1858-4063$

EISSN : 2503-0949

Vol. 14, No. 1, April 2018

2009).

Ozsomer (2012) menyatakanPerceived Qualityterhadap merek global dan merek lokal tidak dapat ditinjau dari satu sisi saja. Hal ini sesuai dengan penelitian yang dilakukan oleh Putri dan Prihastuti (2012) yang menyatakan bahwa ketika hasil menunjukkan tidak terdapat perbedaan Perceived Quality konsumen pada merek global dan merek lokal bukan berarti tidak terdapat perbedaan sama sekali, namun ketika dianalisa perdimensi dapat dilihat terdapat perbedaan Perceived Quality merek global dan merek lokal. Analisa Perceived Quality perdimensi ini didapatkan dari hasil kategorisasi berdasarkan frekuensi jawaban konsumen.Didapatkan hasil bahwa pada dimensi performance dan durability merek lokal memiliki tingkat Perceived Quality yang lebih tinggi.Merek lokal dianggap memiliki kinerja yang lebih baik dan lebih fleksibel digunakan dalam situasi sehari-hari, seperti produk kosmetik sesuai dengan harapan konsumen serta memiliki harga yang cukup murah. Selanjutnya pada dimensi reliability, serviceability dan fit and finish merek global memiliki tingkat Perceived Quality yang lebih tinggi. Merek global dianggap sebagai solusi masalah kulit dan konsisten pada setiap pemakaian serta pelayanan yang diberikan oleh pramuniaga yang cukup baik dan mampu memberikan informasi yang jelas pada pembeli. Sedangkan pada dimensi features merek global dan lokal memiliki tingkat Perceived Quality yang sama-sama tinggi yaitu kedua merek tersebut memiliki kemudahan saat diaplikasikan.

Hasil penelitian Putri \& Prihastuti (2012) sejalan dengan hasil penelitian ini yang menunjukkan bahwa berdasarkan dimensi Perceived Quality diketahui bahwa make up Xunggul dalam performance, conformance with specification, realibility dan durability. Make upX sebagai merek global sebagai merek global dinilai memiliki kinerja yang lebih baik dan konsisten, lebih fleksibel digunakan dalam berbagai situasi dan kondisi serta lebih dapat di andalkan sebagai solusi masalah kulit dan memberikan hasil yang semestinya. Make up $\mathrm{Y}$ sebagai merek lokal unggul dalamfeatures, serviceability, dan fit and finish.Make up Y sebagai merek lokal dinilai lebih praktis dalam penggunaan sehari-hari, memiliki pelayanan yang lebih baik dan pramuniagamake up $\mathrm{Y}$ dinilai mampu memberikan 
informasi yang jelas kepada konsumen selanjutnya make up $\mathrm{Y}$ dinilai memiliki desain dan kemasan yang menarik.

\section{Kesimpulan dan Saran}

\section{Kesimpulan}

Penelitian ini bertujuan untuk melihat perbedaan Perceived Quality konsumen yang menggunakan make up $\mathrm{X}$ dan $\mathrm{Y}$. Hasil penelitian ini menunjukkan bahwa tidak terdapat perbedaan Perceived Quality konsumen yang menggunakan make up $\mathrm{X}$ dan $\mathrm{Y}$. Namun ketika dianalisa perdimensi dapat dilihat terdapat perbedaan tingkat Perceived Quality konsumen yang menggunakan make up $X$ dan Y. Pada dimensi performance, conformance with spesification, reliability, dan durability, merek make upX memiliki tingkat Perceived Quality yang lebih tinggi, sementara itu pada dimensi features, serviceability dan fit and finish, merekmake up Y memiliki tingkat Perceived Quality yang lebih tinggi.

\section{Saran}

Beberapa saran yang disampaikan oleh peneliti terhadap beberapa pihak yang terkait dengan penelitian ini. Berikut saran yang dipaparkan oleh peneliti yaitu kepada perusahaan merek $\mathrm{X}$ (global) dan $\mathrm{Y}$ (lokal)diharapkan dapat memperhatikan Perceived Quality dalam produk maupun jasa yang diberikan kepada konsumen agar merek tersebut mampu bertahan di pasar serta kepada peneliti selanjutnyayang memiliki ketertarikan untuk melakukan penelitian selanjutnya sebaiknya memiliki lebih banyak kajian mengenai Perceived Quality sehingga dapat menghasilkan instrumen penelitian yang lebih representatif dalam mengungkapkan Perceived Quality konsumen, penelitidapat melakukan penelitian Perceived Quality konsumen tidak hanya pada suatu merek kosmetik, tetapi juga pada merek-merek lainnya baik yang menghasilkan produk ataupun jasa, juga dapat melakukan penelitian yang serupa dengan merek yang berbeda secara signifikan serta peneliti juga dapat melihat hubungan antara Perceived Qualitydengan variabel-variabel penelitian lainnya, seperti keputusan pembelian, kepuasan konsumen, minat beli ulang dan lain-lain. 
ISSN : $1858-4063$

EISSN : 2503-0949

Vol. 14, No. 1, April 2018

\section{DAFTAR PUSTAKA}

Aaker. (1991). Managing brand equity : capitalizing on the value of a brand name. New York : London Toronto Sidney

Azwar. (2011). Penyusunan skala psikologi ed 1. Yogyakarta : Pustaka Pelajar

Azwar. (2013). Penyusunan skala psikologi ed 2. Yogyakarta : Pustaka Pelajar

Belopa. (2015). Hubungan kepercayaan merek dan persepsi kualitas dengan minat beli ulang produk kecantikan silver internasional clinic Balik papan. E Journal Psikologi. 3(2), 659-671

Cateora, (2007).Pemasaran internasional. Jakarta : Salemba Empat

Chao \& Schor (1996). Empirical test of status consumption : evidence of women cosmetics. Working Paper.University of Tillburg. Netherland

Durianto. (2004). Strategi menaklukkan pasar melalui riset ekuitas dan perilaku merek Cetakan ketiga. Jakarta : PT Gramedia Pustaka Utama

Ferrinadewi. (2005). Atribut produk yang dipertimbangkan dalam pembelian kosmetik dan pengaruhnya pada kepuasan konsumen di surabaya. Jurnal Managemen dan Kewirausahaan. 7(2), 139-151

Habibah \& Sumiati. (2016). Pengaruh kualitas produk dan harga terhadap keputusan pembelian produk kosmetik Wardah di kota Bangkalan Madura. Jurnal Ekonomi dan Bisnis. 1(1), 31-48

Hgau, Mintarti \& Kuleh. (2012). Pengaruh brand loyalty dan perceived quality terhadap keputusan pembelian handphone nokia. JurnalKinerja. 9(2)

Hurlock. (1999). Psikologi perkembangan :suatu perkembangan sepanjang rentang kehidupan. Jakarta :Erlangga

Kotler \& Keller, (2003). Marketing Management. New Jersey : Pearson EducationInc

Korichi, Pelle de Queral, Gazano \& Aubert (2008). Why women use make up : implication of psychological traits in make up functions. Journal Cosmetics Science. 59, 127-13

Lee, Knight \& Kim (2008). Brand analysis of a US global brand in comparison with domestic brands in Mexico, Korea and Japan. Journal of product 
ISSN : $1858-4063$

EISSN : 2503-0949

Vol. 14, No. 1, April 2018

\& brand management. 17(3), 163-174

Nasution. (2011). Faktor-faktor yang mempengaruhi minat masyarakat berbinis dengan sistem multi level marketing/MLM. Jurnal Keuangan dan Bisnis, 3(1)

Ozsomer. (2012). The interplay between global and local brands : a closer look at perceived brand globalness and local iconness. Juornal of International Marketing. 20(2), 72-95

Papalia, Olds \& Feidman.(2008). Human Development. New York : McGraw

Parasuraman, Zeithaml \& Berry. (1998). Servqual : a multiple-item scale for measuring consumer perception of service quality. Journal of Retaining. 64(1)

Pramuningtias, (2007). Perbedaan tingkat kepercayaan diri pada remaja putri dilihat dari pemakaian kosmetika wajah. Naskah Publikasi Skripsi. Yogyakarta

:Fakultas Psikologi Universitas Sanata Dharma.

Putri \& Prihastuty. (2014). Perceived quality konsumen terhadap local cosmetic brand dan global cosmetic brand (studipada Martha tilaar dan the body shop). Journal of Social and Industrial Psychology. 3(1).

Roy \& Chau. (2011). Consumer-based brand equity and status-seeking motivation for a global versus local brand. Asia Pacific Journal of Marketing and Logistics. 23(3), 270-284

Schiffman \& Kanuk.(2004). Consumer behavior, internasional edition. New Jersey : Pearson Prentice Hall

Sugiono. (2013). Satitistika untuk penelitian.Bandung : Alfabeta

Sunartio, Sukmto \& Dianovinina.(2011). Social comparison dan body dissatisfaction pada wanita dewasa awal. Jurnal Humanitas. 9(2), 157168

Sulistyari \& Yoestini. (2012). Analisis pengaruh citra merek, kualitas produk, dan harga terhadap minat beli produk oriflamme (studi kasus mahasiswi fakultas ekonomika dan bisnis jurusan managemen universitas diponegoro semarang). Diponegoro Journal of Management. 1(1), 1-17

Syahputri, (2013). Pengaruh kualitas produk terhadap citra merek dan keputusan pembelian kosmetik wardah. Naskah Publikasi Skripsi. Medan :Fakultas Ilmu Sosial dan Ilmu Politik Universitas Sumatera Utara 
Tarmedi \& Asri (2002). Pengaruh perceived quality dari brand equity terhadap keputusan pembelian deterjen bukrim. Jurnal Pendidikan Managemen Bisnis. 8(15), 36-100

Tati, Suharyono \& Yulianto. (2015). Pengaruh country of origin dan global bran image terhadap minat beli dan keputusan pembelian (survey pada konsumen yang membeli smartphone Samsung galaxy di asia tenggara). Jurnal Administrasi Bisnis (JAB). 25(1)

Wardah beauty, (2013). Diakses pada 24 November 2016 dari http://www.wardahbeauty.com/

Wulansari \& Budiadi. (2015). Pengaruh persepsi iklan di televisi produk kosmetik wardah terhadap keputusan pembelian produk kosmetik wardah (studi pada mahasiswi UKKI angkatan 2011-2014 universitas negeri surabaya). Jurnal Managemen. 15(1),

Yoo, Donthu \& Lee. (2000). An examination of selested marketing mix elements and brand equity. Journal of the Academy of Marketing Science. 28(2), 195-211

Zareein \& Ashtiani. (2015). Consumer perceptions of global and local brands. Indian Journal of Fundamental and Applied Life Sciences. 5, 4247-4255 